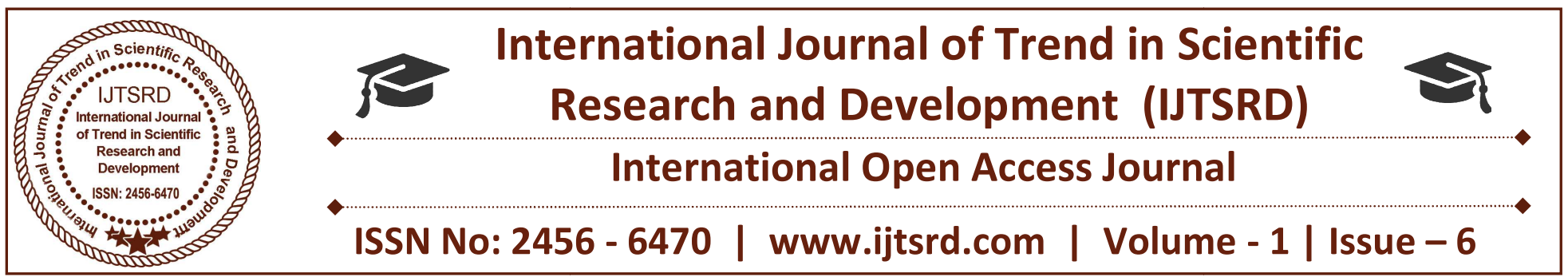

\title{
Suggested Preventive Guidelines for Diabetic Foots among High Risk Patients in Port-Said City
}

\author{
Dr. Shereen Ahmed Qalawa \\ Assisstant Professor, Department of Medical - \\ Surgical Nursing, Faculty of Nursing, \\ Port-said University
}

\author{
Dr. Nahed Abdelazem Abdelslam \\ Lecturer, Departments of Community Health \\ Nursing, Faculty of Nursing, \\ Port-said University
}

\begin{abstract} incapacitating chronic complications resulting from poor disease management. It has a social and economic impact on families, health system, and society as a whole in both developing and developed countries. Aim: The present study was carried to Suggested guidelines for preventive measures of diabetic foots among diabetic patients Subject and Methods: A descriptive exploratory research study was carried out on convenience sampling of 200 diabetic patients from the governmental hospitals and Health Care centers in port - Said city were included in this study during six months from the starting of data collection using one tool which includes 4 main parts as follows ; patient's socio-demographic characteristics , circulatory Assessment sheet, Foot risk Assessment for diabetic foot sheet, and observational checklists for diabetic foot risks
\end{abstract}

Introduction: Diabetic foot is one of the most awareness as predictive risk assessment of diabetic

Results: The finding results revealed that there are significant association was found between patient's occupations with their dermatological condition which the majority of high risk patients for diabetic foots were worked. Also, a significant association was found between patient's level of education with their dermatological condition which the majority of high risk patients for diabetic foots were illiterate and patient with regular appointment and make skin assessment are low risk for diabetic foots.

Recommended Guidelines: The present study concluded recommended that there are obvious needs for educational programme to increase diabetic patient's foots aimed at educating patients on foot care and selfmonitoring. In addition to , Patient education reduce incidence rate of foot ulceration as well as callus formation and fungal infection especially in high-risk patients. Otherwise, dermatological and neurological assessment of diabetic patients seems positively influenced by patient awareness and follow-up appointment.

Keywords: Suggested guidelines, prevention, diabetic foot, high risk, patients

\section{INTRODUCTION:}

Diabetic foot is one of the most incapacitating chronic complications resulting from poor disease management. It has a social and economic impact on families, health system, and society as a whole in both developing and developed countries. (Rocha et al, 2009). Care for patients with a chronic disease such as type 2 diabetes is complex and should be organized in such a way that it can fulfill the high demands of diabetes care. (Fokkens, 2011)

Global prevalence of diabetic foot is $6.3 \%$ and the prevalence in North America, Asia, Europe, Africa and Oceania was $13.0 \%, 5.5 \%, 5.1 \%$ and $3.0 \%$ respectively ( Zhang et al ,2017). In India, Foot infection was common among Indian diabetic patients (52\%). A lesser prevalence of peripheral vascular disease $(13 \%)$ among Indians was noted when 
compared with those in western countries (48\%) smoking increases the risk by reducing blood circulation in the legs and reducing sensation in the feet. (Viswanathan, 2004). While in the U.S. Sixty percent of diabetics will have amputations of lower extremities. The incidence of gangrene of the feet in a diabetic is 20 times greater than the incidence in matched controls. The factors responsible for gangrenes development are ischemia, peripheral neuropathy, and secondary infection. Treating these ulcers is costly, with $25 \%$ of all hospital admissions related to diabetic ulcers and complications. The resulting disfigurement is devastating and problematic (Tierney et al., 2005 \& Coles \& Coppinni, 2004).

Factors aggravated the development of diabetic foot ulcers various . These factors can increase the risk of foot ulcer and cause detachment in the skin or impairment in the wound healing. Peripheral neuropathy can cause excessive pressure on some points of the feet and consequently, ischemia can increase the susceptibility to ulceration by impairment in peripheral vascular. In addition, other factors such as poor vision, limited joint movement, inadequate foot coverage and shoes can be susceptive to ulceration in diabetics. The most important point is that $85 \%$ of diabetic foot amputations are preventable with appropriate care and education. Ideal management for prevention and treatment of diabetic foot is as follow: regular perception of foot, determine at risk foot, education to patient and health staff, appropriate foot coverage, and early treatment of foot problems.

\section{(Tabatabaei-Malazy \& Khatib, 2007)}

Diabetic foot ulceration and amputation are a result of complications of diabetes such as peripheral arterial disease (PAD) and neuropathy. About half of all diabetes patients have complications. There are two types of complications, acute and chronic. Acute complications are hyper or hypoglycemia, with good blood-glucose control, this complication can be resolved. An acute hyperglycemia results in fatigue, a feeling of malaise, and thirst. Hypoglycemia results in sweating, trembling, and dizziness. These symptoms are resolved when the glucose levels return to normal levels. (Fokkens, 2011)

Worldwide, the number of lower limb amputations has increased as a result of diabetes. PAD, also known as peripheral vascular disease, is a circulatory problem in which narrowed arteries reduce blood flow to the lower limbs. This can result in poor oxygen circulation and medication delivery thereby impacting the ability to heal and increasing the risk for ulceration. When combined with other factors, such as inadequate self care, poor glucose control, improper footwear, obesity and lack of timely resources, these neuropathic changes may lead to foot ulceration. While the majority of ulcers eventually heal, approximately one third may result in some form of amputation. Moreover, there is a possibility of infection occurring in any foot ulcer in a person with diabetes. Diabetic foot infections require medical attention ranging from minor (e.g., debridement, antibiotics) to major (resection, amputation) intervention (Lipsky et al, 2012).

The most important complications of diabetes mellitus are neuropathy and diabetic foot manifestations of resulting complications range from simple to highly complex, including limb amputations and lifethreatening infections. Foot infections in people with diabetes are common; this creates complex social problems owing to the financial burden resulting from the high cost of treatment and healing (Aguilar, 2009). (See figure 1)

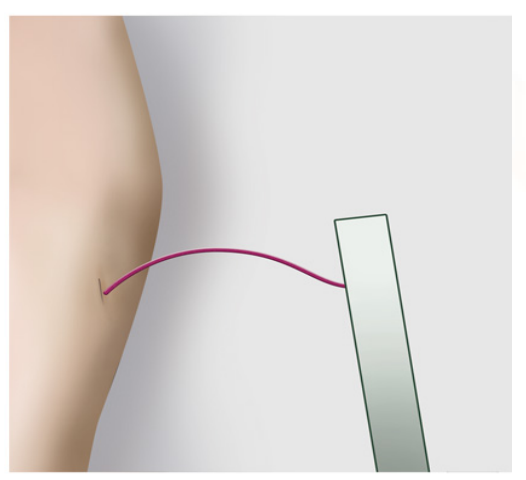

Figure 1: Recommended sites for cutaneous sensory pressure perception testing using a monofilament. Monofilament bent to form a $\mathrm{C}$ shape.

Tesfaye \& Boulton (2013) 
For this regard, a serious challenge for early diagnosis of diabetic patients at high risk of lower limb ulcers is inadequate foot care and foot self-examination. Studies have reported that, in patients diagnosed with diabetes who were admitted to hospitals, $10 \%$ to $19 \%$ of them had their feet examined after footwear and socks were taken off (Rocha et al, 2009 \& Dorresteijn et al, 2014)

Otherwise, Nurses are health care providers who actively involved in prevention and early detection of diabetes and its complications. The nurses' role could be in health care, health, community education, health systems management, patient care and improving the quality of life. Diabetes Nurses play their educating role in the field of prevention of diabetic foot, foot care and preventing from foot injury. In care dimension, nurses responsible for early detection of any changes in skin and foot sensation, foot care, dressing and apply novel technology (Aalaa et al, 2012).

However, regular foot checks, undertaken according to clinical guidelines are important to monitor the health of the feet and reduce the likelihood of complications. The "Get Checked" free annual check should include a foot check if one has not been undertaken during the preceding twelve months (Shahin et al, 2013) . Thus, Recognizing that both foot care knowledge and behaviors are critical for the prevention of lower limb complications in diabetic patients, and that there are scarce Brazilian studies on this subject, the objective of the present study was to assess foot care knowledge and behaviors in diabetic subjects.( Rocha et al, 2009) - Thus, Effective approaches for chronic diseases have often been multi-component, involving combinations of organizational and educational aspects. (Fokkens, 2011)

\section{Significance of Study:}

Foot complications are common in diabetic patients and are associated with a high amputation rate as well as being life threatening. It also accounts for substantial health care cost and resources. It is a major burden to the patient and the healthcare system, the impact of diabetic foot ulcers on quality of life is large, especially on physical functioning, social functioning and mobility. (Shahin et al, 2013).

Additional, Diabetic ulceration of the foot represents a major global medical, social and economic problem. It is the commonest major end-point of diabetic complications. Diabetic neuropathy and peripheral vascular disease are the main etiological factors in foot ulceration and may act alone, together, or in combination with other factors such as microvascular disease, biomechanical abnormalities, limited joint mobility and increased susceptibility to infection. In the diabetic foot, distal sensory polyneuropathy is seen most commonly (Sinwar ,2015)

\section{Aim of the Study}

The present study was carried to suggested guidelines for preventive measures of diabetic foots among diabetic patients through:

1. Assess diabetic patient's practical knowledge regarding preventive measures of Diabetic foots

2. Assess diabetic patient's attitude regarding preventive measures of Diabetic foots

3. Find out the relationship between diabetic patient's knowledge, practice, and attitude regarding preventive measures of diabetic foot and their socio demographic characteristics

4. Suggested guidelines for preventive measures of diabetic patient's regarding preventive measures of Diabetic foots

\section{Research Questions:}

1. What are patient's practical knowledge regarding preventive measures of Diabetic foots?

2. Are there a relation between patient's practice regarding preventive measures of Diabetic foots and their sociodemographic characteristics?

3. Are there a relation between patient's attitude regarding preventive measures of diabetic foots and their sociodemographic characteristics?

\section{Conceptual Definitions:}

\section{Guidelines:}

A statement or other indication of policy or procedure by which to determine a course of action

Preventive Measures: is referred as doing something good to minimize and reduce levels of injuries, illnesses or problems. In health and example of preventative measure is having a healthier diet to minimize risk of type 2-diabetes or stretching muscles to prevent muscle injuries. Within a sporting event and example could include a first aider onsite or someone qualified to administer first aid if required. 
Diabetic Foots : is a foot that exhibits any pathology that results directly from diabetes mellitus or any long-term (or "chronic") complication of diabetes mellitus.[1] Presence of several characteristic diabetic foot pathologies such as infection, diabetic foot ulcer and neuropathic osteoarthropathy is called diabetic foot syndrome.
The Health Belief Model (HBM) remains one of the most widely recognized conceptual frameworks for understanding health behaviour. The HBM identifies four factors that influence the likelihood of preventive health behaviour: perceived susceptibility (perceived vulnerability to a disease or the risks of contracting it); seriousness (perceived severity of the consequences of contracting a disease); benefits (positive results of steps taken to avoid contracting the disease); and barriers (perceived negative aspects of undertaking health behaviours). (Subramanian et al, 2013)

\section{Conceptual Framework}

INIDIVDUAL

PERCEPTIONS
MODIFYING FACTORS

LIKELIHOOD OF

ACTIONS

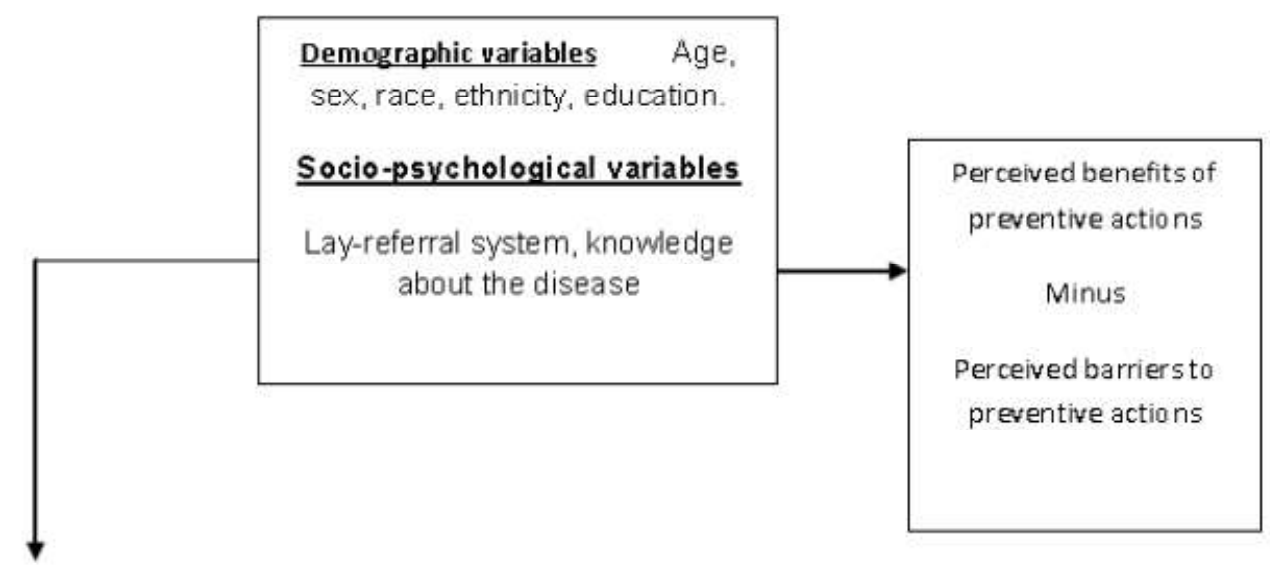

Figure 1.1: Conceptual framework of the Health Belief Model (HBM)

Source: Glanz, Rimer and Lewis 2002:52

Cited In (HAMI, 2012)

\section{SUBJECT AND METHODS}

A Descriptive exploratory research design was used to conduct this study, convenience sampling of 200 diabetic patients from outpatient Diabetic clinics in ( Portsaid general hospital, Port-fouad ) and Health center Diabetic clinics ( AlKwait, Omar Ben ElKhatab , Othman Ben Afan ) at Port - Said city were included in this study with the following criteria:

Both sex patients in age group above 40 years.

$>$ Diabetic patients for more than 5 years

$>$ patients agree to participate in this study

\section{Exclusion criteria:}

Patients with foot amputation

$>$ Patients with foot ulcer, cellulites, neuropathy

\section{Tool of data collection:}

One tool was used for conducted this study. It was adapted from (Boulton et al, 2004 \& Preece \& Bushell, 2013and Damir,2011) after modified them to simple Arabic language for the diabetic patients to suit their level of understanding. Data were collected 
through using one tool which includes 4 main parts as follows:

\section{Part I:}

It includes patient's socio-demographic characteristics, as age, level of education, occupation, duration of diabetes experience, residence, income, past medical history and any disease resulting from diabetes as stroke, hypertension, renal disease ,etc.... , family history .

\section{Part II: Circultory Assessment Sheet}

It includes 10 items to assess patient's complains regarding vascular \& Peripheral status as Diabetic patients with signs or symptoms of vascular disease (like Intermittent claudication, Rest Pains, nocturnal pain, cold feet, blanching on elevation of limb \& rubor on dependency, delayed capillary filling, Impending tissue loss or established gangrene ) or absent, weak pulses on screening foot examination should undergo ankle brachial pressure index (ABI) pressure testing scored as 0 for not present to 1 for present , Random Blood Sugar Test , Serum Creatinnie, Urea last 3 months scored as 0 for normal value to 1 for Abnormal value .

\section{Part III: Foot risk Assessment for diabetic foot sheet}

It includes Dermatology and musculoskeletal Assessment for diabetic foot risk which dermatology assessment includes main items to assess patient's foot condition regarding Posture, gesture, walking and skin status as skin color, erythematic, sweating, thickness, and nail condition as neuropathy signs, infection, ulceration or areas of abnormal erythema. The presence of cellulites or callus (particularly with hemorrhage), nail dystrophy, ingrown toe nail or paronychia , Focal or global skin temperature differences between one foot and assess vascular disease, assess Local Skin temperature for any judged crudely by back of the hand, and foot hair condition scoed as 0 for not present to 1 for present. While musculoskeletal assessment includes 10 items to assess muscloskeletal condition of foot to detect any Foot Deformities as inspect prescence of Hammer Toe or ClawToe, muscle twisting, Charcot arthropathy. Presence of a unilateral red, hot, swollen, flat foot with profound deformity. A rocker-bottom deformity. Scored as 0 for not present to 1 for present.
Part V: observational checklists for diabetic foot risks

It used 5 LOPS neurological assessment tests adapted from (Boulton et al ,2004 \& Damir,2011) after some modifications according to the availability equipments to made the tests which excluded VPT (Vibration Perception Threshold Test ) because the device unavailable. So the LOPS includes 4 tests to detect Peripheral neuropathy through using loss of protective sensation (LOPS) rather than early neuropathy. as 10g monofilament, Pinprick Sensation, Ankle reflexes and Tuning Fork Test

\section{Methods of data collection:}

This study was covered in four phases:-

1. Validity of tool:-. 5 experts were review the content validity of the tool from podiatrists medicine and medical surgical nursing professor in the field after translation of the tool from English to Arabic language.

\section{Reliability:}

Was carried out through using Cronbach alpha test $=$ 0.088

\section{Ethical considerations:}

Approval was taken from hospital \& health center directors before starting the research and data were collected after explaining the aim of the study to all patients who participated in the study.

\section{Pilot study: -}

Pilot study was carried out after the development of the tools on $10 \%$ of the diabetic patients to test applicability of the tools then necessary modification were done according to the results of the results of pilot study and expertise opinions. The purpose of pilot study was:

a. To test the applicability of the study tools.

b. To estimate any need for addition in the tool.

Otherwise, those patients were then excluded from the sample of research work to assure the stability of answers

5. Field work : data were collected from outpatient Diabetic clinics in ( Portsaid general hospital , Portfouad ) and Health center Diabetic clinics ( AlKwait , Omar Ben ElKhatab , Othman Ben Afan ) at Port Said city at six months from September 2016 until February 2017 for two days weekly mainly Sunday 
and Thursday in the morning, each week according to time available to the researchers . Each patient takes time approximately between 20-30 minutes to fill a questionnaire and 15 minutes for observational checklist.

\section{Statistical Analysis:}

Data was collected and entered into a database file. Statistical analysis was performed using the SPSS 19 computer software statistical package. Data was described by summary tables and figures, Chi-2 was used to test the association between two qualitative variables and Monte Carlo for Chi square test, Chi square test was used to compare between two or more proportion. Statistical significance was considered at $\mathrm{P}$-value $<0.05$

\section{Results:}

Table (1): shows that there are near two- third $(65.1 \%)$ of sample were male , about $(42.5 \%)$ in age group between $50-50$ years, near half $(46.5 \%)$ had secondary level of education. While, $(89.0 \%)$ of them were married and $(87 \%)$ life With their wife and sons , finally , (93.5\%) of them have enough income .

Table (2): revealed that there are a statistically significant relation were found between patient's age and presence of Charcot's foot in muscloskeltal assessment while there are a statistically significant relation between diabetic patient's level of education and all musculoskeletal condition

Table (3): revealed that there are a statistically significant relation were found between diabetic patient's level of education and occupation and all items of foot neurological assessment Test (LOPS)

Figure (1): Revealed that there are significant association was found between patient's occupations with their dermatological condition which the majority of high risk patients for diabetic foots were worked.

Figure (2): Revealed that there area significant association was found between patient's level of education with their dermatological condition which the majority of high risk patients for diabetic foots were illiterate.

Figure (3): Revealed that there are a significant association was found between patient's follow-up regularly with their dermatological condition which the patient with regular appointment and make skin assessment are low risk for diabetic foots

Table (1): Sociodemographic characteristics of diabetic patients

\begin{tabular}{|c|c|c|}
\hline & No. & $\%$ \\
\hline \multicolumn{3}{|l|}{ Age } \\
\hline$<\mathbf{3 0}$ & 14 & 7.0 \\
\hline $30-40$ & 30 & 15.0 \\
\hline $40-50$ & 85 & 42.5 \\
\hline $50-60$ & 42 & 21.0 \\
\hline$\geq \mathbf{6 0}$ & 29 & 14.5 \\
\hline Min. - Max. & \multicolumn{2}{|c|}{$18.0-85.0$} \\
\hline Mean \pm SD. & \multicolumn{2}{|c|}{$46.49 \pm 10.95$} \\
\hline \multicolumn{3}{|l|}{ Occupation } \\
\hline Not working & 62 & 31.0 \\
\hline Retired & 17 & 8.5 \\
\hline Working & 121 & 60.5 \\
\hline \multicolumn{3}{|c|}{ What type of work? $(n=121)$} \\
\hline Employee & 112 & 92.6 \\
\hline Free work & 2 & 1.7 \\
\hline Craft work & 7 & 5.8 \\
\hline Level of education & & \\
\hline
\end{tabular}


International Journal of Trend in Scientific Research and Development (IJTSRD) ISSN: 2456-6470

\begin{tabular}{|l|l|l|}
\hline Illiterate & 29 & 14.5 \\
\hline Read and writ & 14 & 7.0 \\
\hline Secondary & 93 & 46.5 \\
\hline University & 64 & 32.0 \\
\hline Residence & & \\
\hline With wife & 2 & 1.0 \\
\hline With sons & 20 & 10.0 \\
\hline With relative & 3 & 1.5 \\
\hline Alone & 1 & 0.5 \\
\hline With wife and sons & 174 & 87.0 \\
\hline Marital status & & \\
\hline Single & 5 & 2.5 \\
\hline Married & 178 & 89.0 \\
\hline Widow & 17 & 8.5 \\
\hline Income & & \\
\hline Enough & 187 & 93.5 \\
\hline Not enough & 13 & 6.5 \\
\hline
\end{tabular}

Table (2): Relation between patient's age, occupation, level of education and their foot musculoskeletal condition

\begin{tabular}{|c|c|c|c|c|c|c|c|c|c|c|c|c|c|c|c|c|c|c|c|c|c|c|c|}
\hline \multirow{3}{*}{$\begin{array}{c}\text { Musculoskeletal } \\
\text { Assessment }\end{array}$} & \multicolumn{9}{|c|}{ Age } & \multicolumn{6}{|c|}{ Occupation } & \multicolumn{8}{|c|}{ Level of education } \\
\hline & \multicolumn{2}{|c|}{$\begin{array}{l}<30 \\
(n= \\
14)\end{array}$} & $\begin{array}{c}30- \\
40 \\
(n= \\
30)\end{array}$ & \multicolumn{2}{|c|}{$\begin{array}{c}40- \\
50 \\
(n= \\
85)\end{array}$} & \multicolumn{2}{|c|}{$\begin{array}{c}50- \\
60 \\
(n= \\
42)\end{array}$} & \multicolumn{2}{|c|}{$\begin{array}{l}\geq 60 \\
\text { (n = } \\
29)\end{array}$} & \multicolumn{2}{|c|}{$\begin{array}{c}\text { Worki } \\
\text { ng } \\
(\mathrm{n}= \\
121)\end{array}$} & \multicolumn{2}{|c|}{$\begin{array}{c}\text { Retire } \\
d \\
(n= \\
17)\end{array}$} & \multicolumn{2}{|c|}{$\begin{array}{c}\text { Not } \\
\text { worki } \\
\text { ng } \\
(n= \\
62)\end{array}$} & \multicolumn{2}{|c|}{$\begin{array}{c}\text { Illitera } \\
\text { te } \\
(n= \\
29)\end{array}$} & \multicolumn{2}{|c|}{\begin{tabular}{|c|}
$\begin{array}{c}\text { Read } \\
\text { and }\end{array}$ \\
write \\
$(\mathrm{n}=$ \\
$14)$ \\
\end{tabular}} & \multicolumn{2}{|c|}{$\begin{array}{l}\text { Secon } \\
\text { dary } \\
(\mathrm{n}= \\
93)\end{array}$} & \multicolumn{2}{|c|}{$\begin{array}{l}\text { University } \\
(n=64)\end{array}$} \\
\hline & No & $\%$ & \begin{tabular}{|c|c|} 
No & $\%$ \\
\end{tabular} & & $\%$ & $\begin{array}{c}\text { No } \\
.\end{array}$ & $\%$ & No & $\%$ & No & $\%$ & No & $\%$ & $\begin{array}{c}\text { No } \\
\text {. }\end{array}$ & $\%$ & No & $\%$ & No & $\%$ & $\begin{array}{c}\text { No } \\
\text {. }\end{array}$ & $\%$ & $\begin{array}{c}\text { No } \\
\text {. }\end{array}$ & $\%$ \\
\hline Hammer toe & 0 & 0.0 & 00.0 & 1 & 1.2 & 2 & 4.8 & 3 & $\begin{array}{l}10 \\
.3\end{array}$ & 2 & 1.7 & 1 & 5.9 & 3 & 4.8 & 3 & 6.9 & 2 & $\begin{array}{c}14 . \\
3\end{array}$ & 2 & 2.2 & 0 & 0.0 \\
\hline$\chi^{2}\left({ }^{\mathrm{MC}} \mathrm{p}\right)$ & \multicolumn{9}{|c|}{$5.968(0.090)$} & \multicolumn{6}{|c|}{$2.682(0.308)$} & \multicolumn{8}{|c|}{$8.211^{*}\left(0.023^{*}\right)$} \\
\hline Claw toe & 0 & 0.0 & 00.0 & 0 & 0.0 & 0 & 0.0 & 0 & $\begin{array}{l}0 . \\
0\end{array}$ & 0 & 0.0 & 0 & 0.0 & 0 & 0.0 & 0 & 0.0 & 0 & 0.0 & 0 & 0.0 & 0 & 0.0 \\
\hline$\chi^{2}\left({ }^{\mathrm{MC}} \mathrm{p}\right)$ & \multicolumn{9}{|c|}{-} & & \multicolumn{8}{|c|}{-} \\
\hline Charcot's Foot & 0 & 0.0 & 00.0 & 4 & 4.7 & 7 & $\begin{array}{c}16 . \\
7\end{array}$ & 7 & \begin{tabular}{|l|}
24 \\
.1 \\
\end{tabular} & 6 & 6.5 & 4 & $\begin{array}{c}23 . \\
5\end{array}$ & 8 & $\begin{array}{c}12 . \\
9\end{array}$ & 4 & $\begin{array}{c}13 \\
8\end{array}$ & 5 & $\begin{array}{c}35 . \\
7\end{array}$ & 8 & 8.6 & 1 & 1.6 \\
\hline$\chi^{2}(\mathrm{p})$ & \multicolumn{9}{|c|}{$14.955^{*}\left({ }^{M C} p=0.001^{*}\right)$} & \multicolumn{6}{|c|}{$7.948^{*}\left(0.019^{*}\right)$} & \multicolumn{8}{|c|}{$14.600^{*}\left(0.001^{*}\right)$} \\
\hline Deformity & 0 & 0.0 & 00.0 & 2 & 2.4 & 2 & 4.8 & 4 & $\begin{array}{l}13 \\
.8\end{array}$ & 2 & 1.7 & 0 & 0.0 & 6 & 9.7 & 3 & $\begin{array}{c}10 \\
3\end{array}$ & & $\begin{array}{c}28 \\
6\end{array}$ & 0 & 0.0 & 1 & 1.6 \\
\hline$\chi^{2}\left({ }^{\mathrm{MC}} \mathrm{p}\right)$ & \multicolumn{9}{|c|}{$6.650(0.069)$} & \multicolumn{6}{|c|}{$6.018^{*}\left(0.036^{*}\right)$} & \multicolumn{8}{|c|}{$19.604^{*}\left(<0.001^{*}\right)$} \\
\hline
\end{tabular}

$\chi^{2}, \mathrm{p}: \chi^{2}$ and $\mathrm{p}$ values for Chi square test

${ }^{\mathrm{MC}} \mathrm{p}$ : $\mathrm{p}$ value for Monte Carlo for Chi square test $\quad *$ : Statistically significant at $\mathrm{p} \leq 0.05$ 
International Journal of Trend in Scientific Research and Development (IJTSRD) ISSN: 2456-6470

Table (3): Relation between patient's age, occupation, level of education and their foot neurological assessment Test (LOPS)

\begin{tabular}{|c|c|c|c|c|c|c|c|c|c|c|c|c|c|c|c|c|c|c|c|c|c|c|c|c|}
\hline \multirow{3}{*}{$\begin{array}{l}\text { Simple bed } \\
\text { clinical tests for } \\
\text { LOPS }\end{array}$} & \multicolumn{10}{|c|}{ Age } & \multicolumn{6}{|c|}{ Occupation } & \multicolumn{8}{|c|}{ Level of education } \\
\hline & \multicolumn{2}{|c|}{$\begin{array}{c}<30 \\
(n=14)\end{array}$} & \multicolumn{2}{|c|}{$\begin{array}{l}30-40 \\
(n=30)\end{array}$} & \multicolumn{2}{|c|}{$\begin{array}{l}40-50 \\
(n=85)\end{array}$} & \multicolumn{2}{|c|}{$\begin{array}{l}50-60 \\
(n=42)\end{array}$} & \multicolumn{2}{|c|}{$\begin{array}{c}\geq 60 \\
(n=29)\end{array}$} & \multicolumn{2}{|c|}{$\begin{array}{c}\text { Workin } \\
\mathrm{g} \\
(\mathrm{n}= \\
121)\end{array}$} & \multicolumn{2}{|c|}{$\begin{array}{l}\text { Retired } \\
(n=17)\end{array}$} & \multicolumn{2}{|c|}{$\begin{array}{c}\text { Not } \\
\text { working } \\
(\mathrm{n}=62)\end{array}$} & \multicolumn{2}{|c|}{\begin{tabular}{|c|} 
Illiterat \\
$e$ \\
$(n=29)$
\end{tabular}} & \multicolumn{2}{|c|}{$\begin{array}{c}\text { Read } \\
\text { and } \\
\text { write } \\
(n=14)\end{array}$} & \multicolumn{2}{|c|}{$\begin{array}{l}\text { Second } \\
\text { ary } \\
(n=93)\end{array}$} & \multicolumn{2}{|c|}{$\begin{array}{c}\text { Universit } \\
y \\
(n=64)\end{array}$} \\
\hline & No. & $\%$ & No & $\%$ & No. & $\%$ & No. & $\%$ & No & $\%$ & No. & $\%$ & No & $\%$ & No & $\%$ & No & $\%$ & No & $\%$ & No & $\%$ & No & $\%$ \\
\hline \multicolumn{25}{|l|}{$\begin{array}{l}10-g \\
\text { monofilament } \\
10-g \\
\text { monofilament }\end{array}$} \\
\hline & 0 & 0.0 & 00 & 0.0 & 6 & 7.1 & 3 & 7.1 & 0 & 0.0 & 8 & 6.6 & 0 & 0.0 & 1 & 1.6 & 0 & 0.0 & 2 & 14.3 & 1 & 1.1 & 6 & 9.4 \\
\hline & 14 & 100 & 30 & 100 & 79 & 92.9 & 39 & 92.9 & 29 & 100 & 113 & $\begin{array}{c}93 . \\
4\end{array}$ & 17 & 100 & 61 & 98.4 & 29 & 100 & 12 & 85.7 & 92 & 98.9 & 958 & 90.6 \\
\hline$\chi^{2}(\mathrm{p})$ & \multicolumn{10}{|c|}{$\frac{1}{3.859(0.356)}$} & \multicolumn{6}{|c|}{$2.257\left({ }^{\mathrm{vll}} \mathrm{p}=0.341\right)$} & \multicolumn{8}{|c|}{$\begin{array}{ll}\mid & \mid \\
& 9.577\left({ }^{\mathrm{vNL}} \mathrm{p}=0.011\right)\end{array}$} \\
\hline $\begin{array}{l}\text { Pinprick } \\
\text { Sensation }\end{array}$ & & & & & & & & & & & & & & & & & & & & & & & & \\
\hline Exist & 1 & 7.1 & 6 & 20.0 & 10 & 11.8 & 5 & 11.9 & 1 & 3.4 & 20 & $\begin{array}{c}16 . \\
5\end{array}$ & 1 & 5.9 & 2 & 3.2 & 0 & 0.0 & 3 & 21.4 & 8 & 8.6 & 12 & 18.8 \\
\hline Not exist & 13 & 92.9 & 24 & 80.0 & 75 & 88.2 & 37 & 88.1 & 28 & 96.6 & 101 & $\begin{array}{c}83 . \\
5\end{array}$ & 16 & 94.1 & 60 & 96.8 & 29 & $\begin{array}{c}100 . \\
0\end{array}$ & 11 & 78.6 & 85 & 91.4 & 452 & 81.3 \\
\hline$\chi^{2}(\mathrm{p})$ & \multicolumn{10}{|c|}{$3.925(0.395)$} & \multicolumn{6}{|c|}{$7.704(0.021)$} & \multicolumn{8}{|c|}{$9.693(0.016)$} \\
\hline $\begin{array}{l}\text { Ankle reflexes } \\
\text { Exist }\end{array}$ & 11 & 78.6 & 25 & 83.3 & 77 & 90.6 & 32 & 76.2 & 17 & 58.6 & 105 & $\begin{array}{c}86 . \\
8\end{array}$ & 10 & 58.8 & 47 & 75.8 & 15 & 51.7 & 11 & 78.6 & 27 & 82.8 & 859 & 92.2 \\
\hline Not exist & 3 & 21.4 & 5 & 16.7 & 8 & 9.4 & 10 & 23.8 & 12 & 41.4 & 16 & $\begin{array}{c}13 . \\
2\end{array}$ & 7 & 41.2 & 15 & 24.2 & 14 & 48.3 & 3 & 21.4 & 16 & 17.2 & 25 & 7.8 \\
\hline$\chi^{2}(p)$ & \multicolumn{10}{|c|}{$15.306(0.004)$} & \multicolumn{6}{|c|}{$9.143(0.010)$} & \multicolumn{8}{|c|}{$21.604(<.001)$} \\
\hline \multicolumn{25}{|l|}{$\begin{array}{l}\text { Tuning Fork } \\
\text { Test Tuning } \\
\text { Fork Test }\end{array}$} \\
\hline Exist & 11 & 78.6 & 22 & 73.3 & 70 & 82.4 & 30 & 71.4 & 15 & 51.7 & 99 & $\begin{array}{c}81 . \\
8\end{array}$ & 8 & 47.1 & 41 & 66.1 & 13 & 44.8 & 11 & 78.6 & 71 & 76.3 & 353 & 82.8 \\
\hline Not exist & 3 & 21.4 & 8 & 26.7 & 15 & 17.6 & 12 & 28.6 & 14 & 48.3 & 22 & $\begin{array}{c}18 . \\
2\end{array}$ & 9 & 52.9 & 21 & 33.9 & 16 & 55.2 & 3 & 21.4 & 22 & 23.7 & 711 & 17.2 \\
\hline$\chi^{2}(\mathrm{p})$ & & & & 10.8 & 865 & $(0.02 \varepsilon$ & 8) & & & & & 12.2 & 254 & $(0.00$ & $02)$ & & & & & 5.828 & $(0.0$ & $001)$ & & \\
\hline
\end{tabular}

$\chi^{2}, \mathrm{p}: \chi^{2}$ and $\mathrm{p}$ values for Chi square test

${ }^{\mathrm{MC}} \mathrm{p}$ : $\mathrm{p}$ value for Monte Carlo for Chi square test $\quad *$ : Statistically significant at $\mathrm{p} \leq 0.05$ 


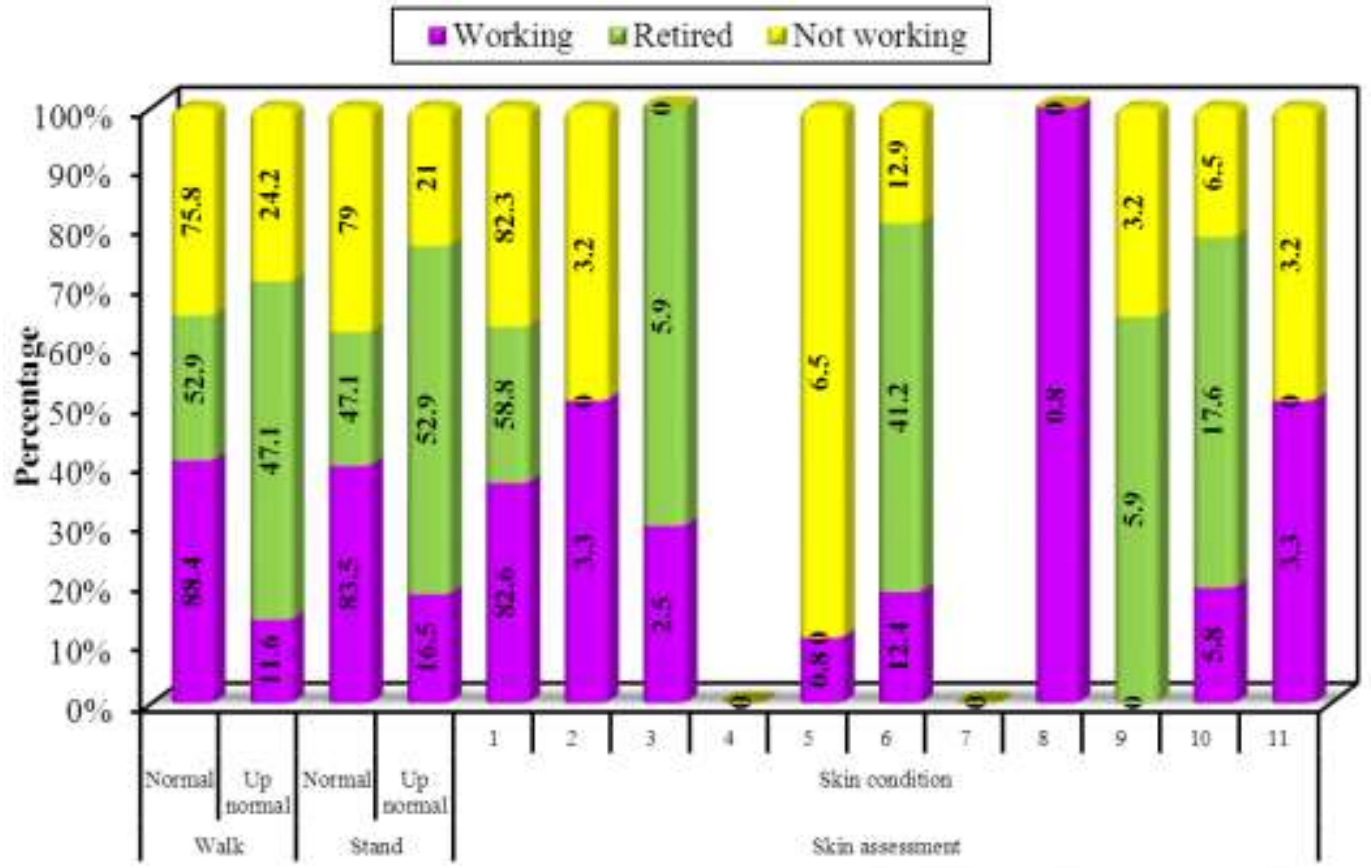

Figure (1): Relation between patient's occupation with their dermatological condition

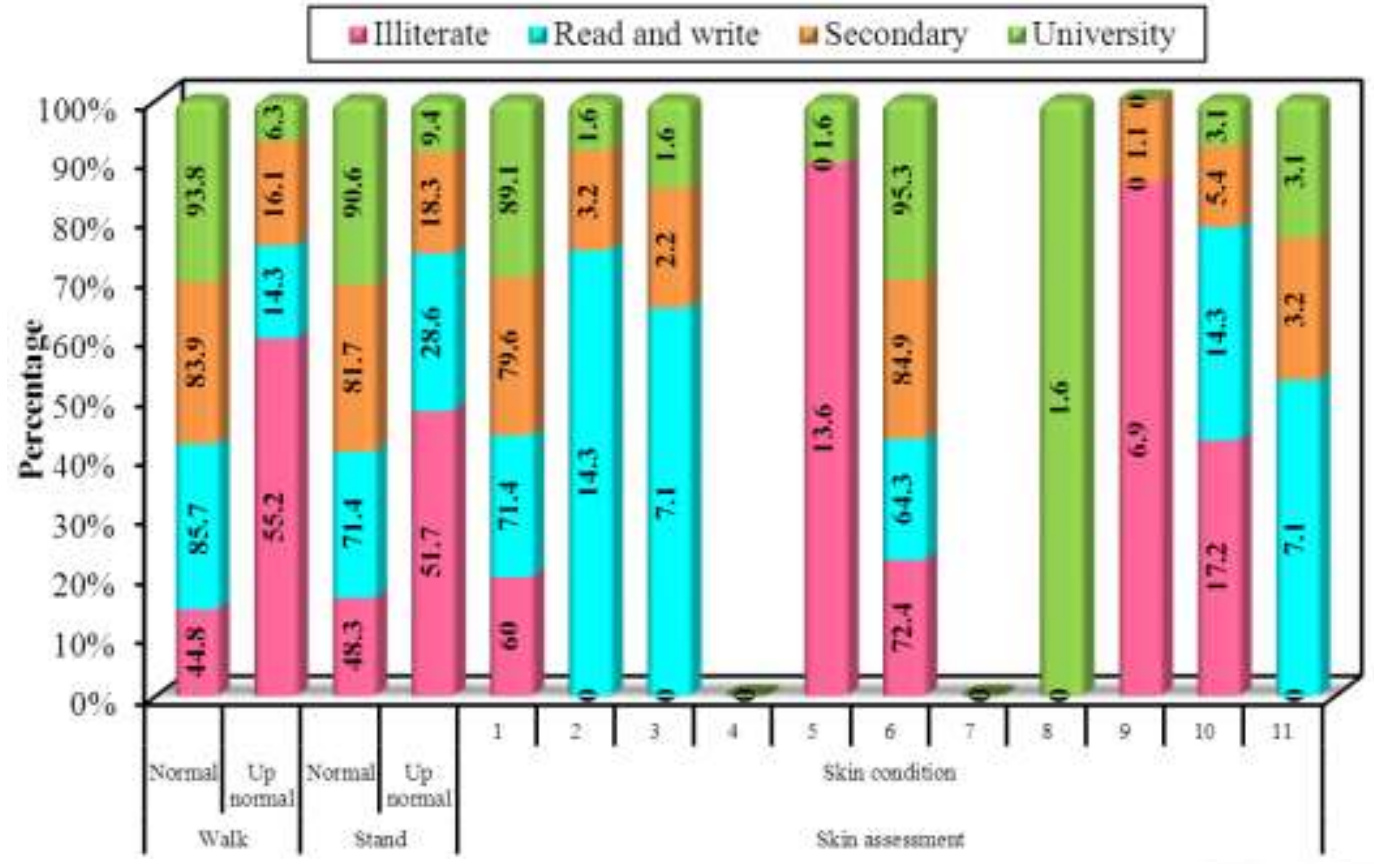

Figure (2): Relation between patient's levels of education with their dermatological condition 


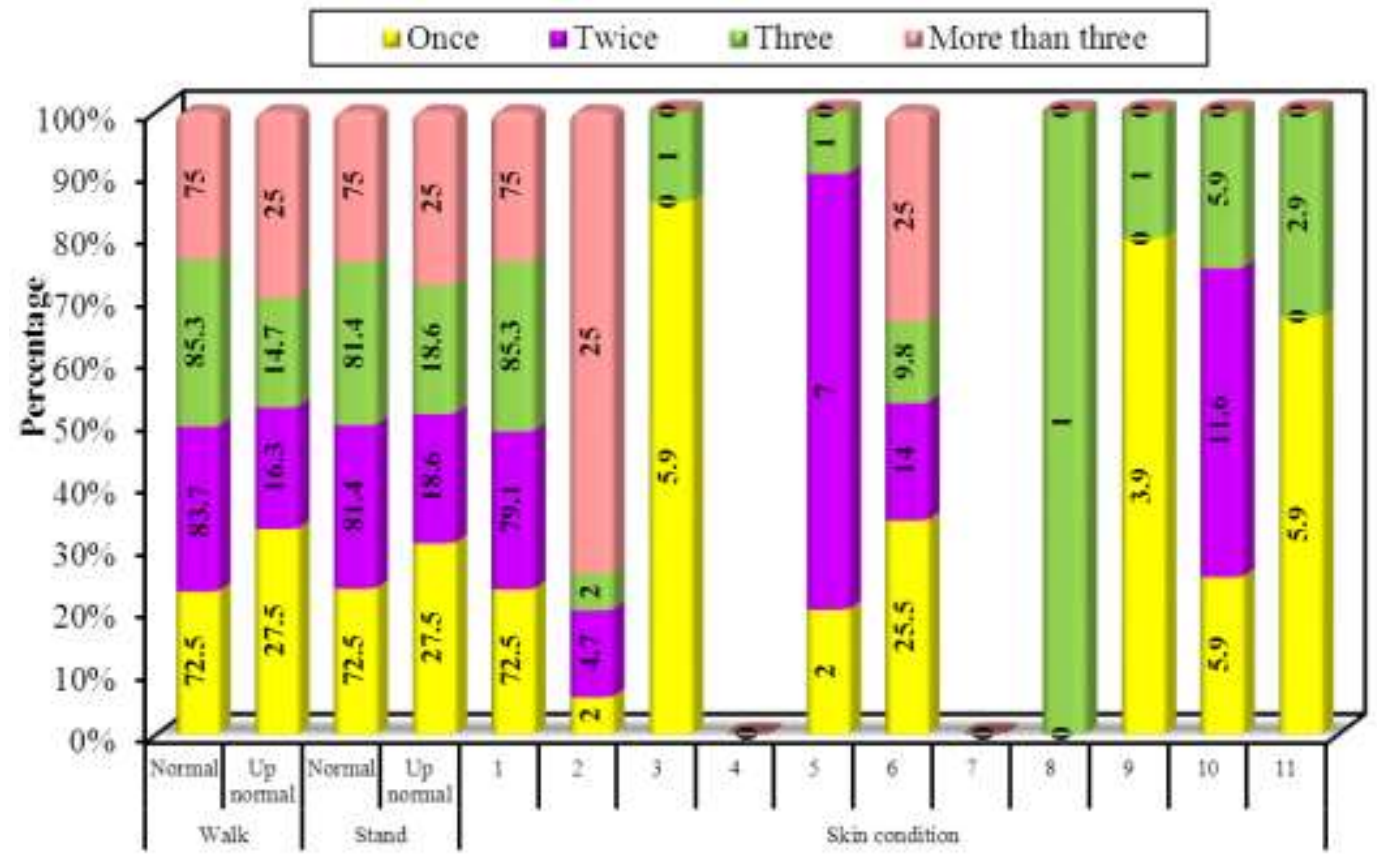

Figure (3): Relation between patient's follow up patterns with their dermatological condition

\section{Discussion:}

Diabetic foot is a severe public health issue, yet rare studies investigated its global epidemiology. The patients with diabetic foot ulcer were older, had a lower body mass index, longer diabetic duration, and had more hypertension, diabetic retinopathy, and smoking history than patients without diabetic foot ulceration. Our results provide suggestions for policy makers in deciding preventing strategy of diabetic foot ulceration in the future. (Zhang et al ,2017)

Concerning sociodemographic characteristic of the studied sample the current study revealed that there are near two- third of diabetic patients were male, below half of them in age group between 50-50 years, near half had secondary level of education. While, more than two third of them were married and) life with their wife and sons, finally, the majority of them have enough income

Concerning risk assessment of muskloskeletal condition .The current study revealed that there are a statistically significant relation was found between patient's age and presence of Charcot's foot in muscloskeltal assessment while there are a statistically significant relation between diabetic patient's level of education and all musculoskeletal condition. This finding supported with Zhang et al ,2017 who mentioned that Diabetic foot was more prevalent in males than in females, and more prevalent in type 2 diabetic foot patients than in type 1 diabetic foot patients. The patients with diabetic foot were older, had a lower body mass index, longer diabetic duration, and had more hypertension, diabetic retinopathy, and smoking history than patients without diabetic foot.

Regarding diabetic patient's risk for diabetic foots the present findings revealed that revealed that there are significant association was found between patient's level of education with their dermatological condition which the majority of high risk patients for diabetic foots were illiterate. this findings goes in the same line with Wallace et al. , 2009 who necessitate on the importance of health literacy, successful teaching, literacy-level appropriate patient education with selfmanagement support package, and individual consultation would be necessary for self-management at home with diabetic patients. Also, appropriate educational material should be available for subjects with low literacy levels. In addition, the educational levels of subjects may show greater reliance on less verbal and less abstract form of educational materials. Positive learning outcomes for the tasks were demonstrated in the three groups independent of educational levels of the subjects. 
In relation to, diabetic patients occupation as a risk assessment of diabetic foots regarding dermatological condition. The current study revealed that there are significant association was found between patient's occupations with their dermatological condition which the majority of high risk patients for diabetic foots were worked. This findings goes in the same line with El-Nahas et al , 2008 in Egypt, who mentioned that despite the low prevalence of neuropathy and PAD in our diabetic patients, the prevalence of DFU is still high it might be related to the lack of knowledge regarding diabetic foot problems, inappropriate footwear and the high prevalence of skin and nail pathology could explain this paradox. It is suggested that regional differences in the risk factors for DFU should be considered when preventative strategies are planned.

However, poorly controlled diabetes is prone to skin infections because elevated blood sugar reduces the effectiveness of bacteria fighting cells. Sensory neuropathy, atherosclerotic vascular disease and uncontrolled hyperglycemia are the favoring factors for development of skin and soft tissue infections. Infection can affect any part of the body. But the most common area affected in the feet is skin. It will increase the hospitalization and amputation which in turn result in long term economic, physical, social and mental disability to the patient.( Tamalli et al, 2015)

In relation to diabetic patient's risks and neurological assessment. The present study revealed that there are a statistically significant relation were found between diabetic patient's level of education, occupation and all items of foot neurological assessment Test (LOPS). This finding goes in the same way with Kravitz et al, 2008 who mentioned that LOPS has been correlated with a risk of ulceration, especially in biomechanically unbalanced feet with secondary bony prominences, such as bunions or hammer toes. Patients with LOPS are unable to feel tight socks or shoes, foreign objects in the shoe, or even a puncture from a sharp object. Because these patients do not feel pain, they may continue to walk on small ulcers that enlarge and deepen, increasing the risk of deep space infection or osteomyelitis.

Concerning risk assessment of dermatological system the current study revealed that there are a significant association was found between patient's follow-up regularly with their dermatological condition which the patient with regular appointment and make skin assessment are low risk for diabetic foots. This finding goes in the same way with Abubakari and
Bhopal , 2008 in Ghana and Nigeria who stated that the evidence base points to a rise in diabetes prevalence, with major urban-rural differences. There is an urgent need for accurate and comparable surveys on diabetes and its risk factors among Nigerians and Ghanaians. Effective public health policies are vital to control the diabetes epidemic.

Additionally, Rocha et al, 2009 highlight on the dermatological care as appeventive measures of diabetic foots which inadequate behaviors, 98.2\% wore open home and street footwear, 89.1\% wore seam or seamless footwear, $85.4 \%$ removed their calluses with inappropriate nail files and chemical products, $83.6 \%$ cut their toe nails inappropriately, very short and round, $83.6 \%$ bought footwear in the morning or early afternoon; $80.0 \%$ wore seam dark socks, $78.2 \%$ did not lubricate their feet on a daily basis, $69.1 \%$ trimmed their cuticles, $67.3 \%$ did not examine their feet on a daily basis, and $63.6 \%$ used emollients between their toes. Otherwise, adequate foot care behaviors, more than $50 \%$ of subjects used to dry between their toes, did not use heating pads, wore comfortable soft footwear, and their footwear before wearing them. These findings are consistent with other studies(30) that found diabetic patients were generally aware of the need of adequate foot care but their selfcare was inadequate, even though more than $60 \%$ wore close footwear and $85 \%$ reported foot washing with water and soap and drying them properly.

In Zimbabwe, Sibanda et al ,2009 emphasis on the skin care and prevention of infection which considered as one of the diabetic foot risks for diabetic patients and stated that the main aetiologies were bacterial infection, arterial disease, trauma and neuropathy. Ulcer healing and limb salvage were noted in $71 \%$. Mortality was $10 \%$; seven in HIV-infected and three in non HIV-infected non diabetic patients $(\mathrm{P}=0 \cdot 06)$. Amputation rate was 9\%. Persisting ulcers were noted in $8 \%$ and $2 \%$ were lost to follow-up. Our evaluation shows that wound aetiologies in Zimbabwe differ from those in the West. Immunosuppression because of HIV infection and NIDDM was noted in more than half of the patients. HIV infection may increase mortality in this group of patients.

On the other hands, Coping skills is obvious needs for encouraging diabetic patients to improve self-care behaviour, metabolic outcomes and thereby quality of life. The use of simple clinical tests allows a person with diabetes to understand a developing complication, such as loss of protective sensation in its early stages. 
This gives the knowledge and therefore the option to those with early Type 2 diabetes to make the behavioural changes that may be required to prevent foot problems such as ulceration and amputation.( Thomson et al, 2008)

Finally, recent studies in Saudi Arabia have shown a rampant increase in the number of patients with diabetes around the world. This constitutes an economic burden on the resources of states and hence has prompted many international organizations to devise awareness and educational programs about the dangers of this the disease and ways to deal with it. And found that the majority of examined population has chosen traditional medical intervention rather than herbal medicine in dealing with foot problems. (Hasan, 2017)

\section{Conclusion:}

The present study concluded that there are obvious needs for educational programme to increase diabetic patient's awareness as predictive risk assessment of diabetic foots aimed at educating patients on foot care and self-monitoring. Patient education reduce incidence rate of foot ulceration as well as callus formation and fungal infection especially in high-risk patients. Otherwise, dermatological and neurological assessment of diabetic patients seems positively influenced by patient awareness and follow-up appointment.

\section{Recommended guidelines:}

From the foregoing discussion, we can suggested some guidelines for Diabetic patients, podiatrists , hospital directors, and further research studies as follows:

$>$ Offer standard guidelines in both labeled wall chart and online access to be easily reachable for diabetic patients.

$>$ Encourage Podiatrist nurses and medicine doctors to cooperate together in assess and detect early signs and symptoms of diabetic foots

$>$ Give diabetic patients instructions of how to applying neurological tests and follow -up regarding assess early signs of diabetic foot

$>$ Hospital and health centers administrators to support the outpatient's clinics with facilities and equipments required to dermatological and neurological assessment for prevention of diabetic foots.

$>$ Continuous educational program for health care providers should by introduce to demonstrate neurological assessment and how to use its equipments.

$>$ Every diabetic patient should be directed to haveregular inspection and examination of their feet.

$>$ Argent need for further research and more studies that evaluate the impact of conducting educational programs included the aggravated factors of diabetic foots incidence.

\section{REFERENCES}

1. Fokkens, S. A. (2011). Structured diabetes care in general practice: effects on organization of care and clinical outcomes Groningen: s.n :P.11

2. Aguilar , F . (2009 ) : Diabetic Foot; physiopathology and treatment, In: Diabetic Neuropathy, Practical aspects, treatment, diagnostic and prophylactic measures, Aguilar Rebolledo Francisco , Alfil editorial, ISBN 978-607-7504-566, Mexico: p. 335

3. Lipskey, B. A., Berendt, A. R., Cornia, P. B., Pile, J. C., Peters, E. J. G., Amrstrong, D. G., et al. (2012). 2012 Infectious disease society of America clinical practical guideline for the diagnosis and treatment of diabetic foot infections. Clinical Infectious Diseases, 54(12), 142.

4. Subramanian , P; Masri , A.M; Oranye, N.O; Taib , N.A; Ahmad, N. (2013): Breast Cancer Knowledge and Screening Behaviour among Women with a Positive Family History: A Cross Sectional Study. Asian Pac J Cancer Prev, 14 (11), 6783-6790

5. Viswanathan, V • (2004) : "Need for education on foot care diabetic patients in India" Journal Association of physicians India 47(11):p.41

6. Tierney, L. M., McPhee, S. J., \& Papadakis, M. (2005). 2005 Current medical diagnosis and treatment (44th ed.). The McGraw-Hill Companies, Inc. p. 53

7. Coles, D. R., \& Coppini, D. V. (2004). Survey of hospital admissions related to diabetic foot disease. The Diabetic Foot, 4, p.4.

8. Wallace, A. S., Seligman, H. K., Davis, T.C., Schillinger, D., Arnold, C. L., Bryant-Shillday, B. et al. (2009) : Literacy-appropriate educational materials and belief counseling improve diabetes self managment. Patient Education \& Counseling, 75, 330

9. Rocha RM, Zanetti ML, Santos MA. (2009) " Behavior and knowlege: basis for prevention of diabetic foot . Acta Paul Enferm ;22(1):20. 
10. Aalaa, M; Tabatabaei ,O ; Sanjari, M ; Peimani and MR Mohajeri-Tehrani. (2012) : Nurses' role in diabetic foot prevention and care; a review Journal of Diabetes \& Metabolic Disorders, $11: 24$ http://www.jdmdonline.com/content/11/1/24

11. Khatib O, Tabatabaei-Malazy O: Prevention and public approach to diabetic foot. Iranian $\mathrm{J}$ of Diabetes \& Lipid Disorders 2007, 7(2):123-133

12. Sibanda,M ; Sibanda, E; Jönsson,K .(2009) : A prospective evaluation of lower extremity ulcers in a Zimbabwean population, International wound journal, Volume 6, Issue 5 October 2009 Pages 361-366

13. Hasan , N • (2017) : EVALUATION OF THERAPEUTIC METHODS USED FOR THE TREATMENT OF DIABETIC FOOT SYNDROME, Vol 11, No 02 (2017), Asian Journal of Pharmaceutics , p.1

14. Thomson , M , Potter , J ; Finch , P ; Paisey , R ( 2008): Threshold for detection of diabetic peripheral sensory neuropathy using a range of research grade monofilaments in persons with Type 2 diabetes mellitus, Journal of Foot and Ankle Research 2008, 1:9

15. Abubakari , $\mathrm{R}$;.Bhopal ， R.S.( 2008): Systematic review on the prevalence of diabetes, overweight/obesity and physical inactivity in Ghanaians and Nigerians, Public Health journal, Volume 122, Issue 2, February 2008, Pages 173182

16. Kravitz , S ; Shanahan , S ; McGuire , J ; Kravitz , S.(2008) : Physical Assessment of the Diabetic Foot, advanes in skin \& wound care , 16(2) :p. 68

17. El-Nahas , M ; Gawish , H ; Tarshoby , M; State,O; Boulton, A.(2008): The prevalence of risk factors for foot ulceration in Egyptian diabetic patients, Volume 25, Issue 9 , Pages 362-366, practical diabetes journal
18. Fokkens, S. A. (2011). Structured diabetes care in general practice: effects on organization of care and clinical outcomes Groningen: s.n., published article , University of Groningen, p. $1 * *$

19. Sinwar ， P.D .(2015): The diabetic foot management e Recent advance, International Journal of Surgery, 29, 1. P.1

20. Dorresteijn JAN, Kriegsman DMW, Assendelft WJJ, Valk GD .(2014) : Patient education for preventing diabetic foot ulceration, The Cochrane Collaboration. JohnWiley \& Sons, Ltd.Co , Netherlands., Issue 12

21. Zhang, P; Jing, Y; Tang, S; Jing, L; Zhu ,D ; Bi, Y. (2017): Global epidemiology of diabetic foot ulceration: a systematic review and meta-analysis , Annals of Medicine, Volume 49, Issue 2 , Pages 106-116

22. Tamalli $M * 1$, M.A.B. Gamal2 and Alghazal M. A. (2015): COMMON AEROBIC BACTERIAL ISOLATES FROM DIABETIC FOOT ULCER AND THEIR ANTIBIOTIC SUSCEPTIBILITY TESTING, WORLD JOURNAL OF PHARMACY AND PHARMACEUTICAL SCIENCES , 4 (8)260-266 .

23. Shereen A A Qalawa, Eman S Shahin, Amal Bakr Abo El-Ata, Magda Aly Mohamed. Quality of life $\&$ satisfaction of diabetic foot patients: Comparative study. J Am Sci 2013;9(1):474-483

24. Preece,V ; Bushell, L.(2012): Podiatric Guidelines for the Management of the Diabetic Foot, Worcestershire NHS primary care trust , Page 20

25. Damir , A .(2011) : Clinical Assessment of Diabetic Foot patient, JIMSA October - December 2011 Vol. 24 No. 4 :pp.200-204

26. Boulton AJ, Malik RA, Arezzo JC, Sosenko JM: Diabetic somatic neuropathies. Diabetes Care 27:1458-1486, 2004.

27. Boulton AJ, Tesfaye S, Dickenson A. Mechanisms and management of diabetic painful distal symmetrical polyneuropathy. Diabetes Care 2013;36:2456-65. 